\title{
Post cracking behaviour of fibre reinforced concrete with mineral wool fibers residues
}

\author{
Marta Kosior-Kazberuk ${ }^{1, *}$, Julita Krassowska², and Carolina Piña Ramírez ${ }^{2}$ \\ ${ }^{1}$ Faculty of Civil and Environmental Engineering, Bialystok University of Technology, Bialystok, \\ Poland \\ ${ }^{2}$ Departamento de Construcciones Arquitectónicas y su Control, Escuela Técnica Superior de \\ Edificación, Universidad Politécnica de Madrid, Avda. Juan de Herrera 6, 28040 Madrid, Spain.
}

\begin{abstract}
The research concerns the feasibility of recycling fibers from mineral wool residues from construction and demolition waste, by incorporating them into a fine grained concrete. All the specimens of concrete with various types of fibers have been subjected to the mechanical tests of flexural and compressive strength. Also the pre-cracking and postcracking softening behaviour of concrete with fiber residues has been investigated. The flexural load-CMOD and load-deflection relationships, obtained in three-point bending test, have been used to determine the fracture parameters: fracture energy, critical stress intensity factor, critical crack tip opening displacement, critical effective crack length. It was verified that the incorporation of mineral residues to a cement concrete is a viable alternative for their recycling; the new composites analyzed maintain adequate mechanical properties for different application.
\end{abstract}

\section{Introduction}

The construction of buildings is not only one of the major causes of pollution in Europe, but also one of the largest sources of waste production.

The increasing concerns of society at the environmental level require the search for new alternative materials that help to guarantee the preservation of the environment, and in this sense the Circular Economy strategy [1] is currently the ideal framework for which the building construction sector should aim.

Therefore, it is not only essential to consider the minimization of raw materials consumption in this sector, but also reducing the generation of waste.

In opposite to the current situation of disposing of construction and demolition waste (CDW) in landfill, recycling and reusing them as by-products can be a highly feasible option.

About 890 million tonnes of CDW are generated each year in Europe, with only 50\% being recycled [2], so sustainable material solutions are urgently needed.

On the other hand, in the last decade the use of mineral wool has increased due to stricter thermal and acoustic requirements marked by the norms in the construction of houses [3]. It

\footnotetext{
*Corresponding author: kosior@pb.edu.pl
} 
is estimated that $0.2 \%$ of all CDW generated is mineral wool. Mineral wool represents about $60 \%$ of the insulating materials used in buildings [4]. The waste from this type of insulating materials is characterized by low levels of reuse, recycling rate and recovery methods. In addition, it is estimated that by 2020 , more than 2.5 million ton of mineral wool waste will be generated in the EU-28 area [5].

As a result of this problem and the need for recycling and reusing of materials in the construction industry, cement materials with fiber have been specifically emerging, mainly incorporating fibers of vegetable origin into inorganic matrixes based on cement.

Numerous research works have appeared also looking to replace raw materials of traditional structures with other materials having lower environmental impact $[5,6]$, like those with additions of construction and demolition waste (CDW) [7]. In addition. some of these works discuss the properties of cement composites after adding compounds like waste glass powder [8] or polyethylene [9] in order to decrease the bulk density by additions.

The cementitious materials are characterized by a marked weakness when subjected to tensile or bending stress [10], problems to which the fiber cement could be a solution.

Initially, fibers of mineral origin such as asbestos were incorporated into the mortar and concrete. Their use has been prohibited due to problems of safety and population health [11], but their functioning and properties were very positive due to their high compatibility with the cement matrix [12].

However, it is noted that the potential of fiber reinforced cement composites has not been fully exploited today, mainly due to the lack of specific regulations on building codes and lack of assimilation to the rules for composites unreinforced, since their behavior is markedly non-linear as the fibers begin to work after cracking the cement matrix [13].

Currently, metallic, organic and mineral fibers are used in cement composites. However, none of the fibers used in the previous studies comes from a recycling process.

The mineral wool waste studied in this research is codified by the European Waste List (EWL) as 1706 04, "Insulating material not containing asbestos nor hazardous substances", and it is characterized by low level of reuse, recycling rate and other ways of recovery.

Therefore, this research analyzes the feasibility of recycling mineral wool fibers from construction and demolition waste by incorporating them into a cement mortar matrix [14] as an alternative to commercial fibers found today. Particularly the characteristics of the flexural toughness and fracture energy of the new compounds should be analyzed.

The aim of the study was to evaluate the effect of mineral wool fibers residues on the toughness and post-cracking behavior of concrete. The characteristics of fine grained concrete with mineral wool residues were determined in three-point-bending test on notched beam specimens. The fracture characteristics for concretes with mineral wool fibers residues, such as critical stress intensity factor $K_{I c}$ and crack tip opening displacement $\mathrm{CTOD}_{c}$ were assessed on beams with initial notches in three-point-bending test. The mechanical properties of concretes were determined as well.

\section{Experimental details}

\subsection{Materials and specimen preparation}

The materials used in this study were Portland cement CEM II/BL $32.5 \mathrm{~N}$, river sand of maximum diameter $4 \mathrm{~mm}$, and three types of waste mineral wool residues: glass fiber residue (FG), rock wool residue (RW) and mix of both type of waste (MIX).

The dosage of cement, aggregate and water in all the specimens was 1:3:0.6, and the percentages of fiber addition in substitution of the river sand, measured in volume, were 
$30 \%$ of each waste. The effect of fibers on concrete properties was referred to the results obtained for the reference concrete without fibers.

The waste mineral fibers have been subjected to a pre-treatment by comminuting in a machine of $550 \mathrm{~W}$ power and a rated voltage of $50 \mathrm{~Hz}$, for 3 intervals of 3 minutes each, getting a format suitable to be incorporated into the concrete $(l=500-1000 \mu \mathrm{m})$.

The experimental procedure analyses of the variations in mechanical behavior of concrete made with additions of different types of mineral fiber residues, in order to obtain preliminary conclusions that allow to characterize the composites obtained.

At first, the fiber additions were submerged in water and the cement was then added and mixed manually for 15 seconds. Then, the components were mixed slowly for another 15 seconds, and after adding the aggregate, rapidly for 75 seconds.

The bulk density of the fresh concrete was determined, and it was observed that the value of the density generally decreases with the incorporation of the residues of fibers (Table 1).

Table 1. Bulk density of fresh mortar

\begin{tabular}{|l|l|l|}
\hline \multicolumn{3}{|l|}{ BULK DENSITY OF FRESH MORTAR } \\
\hline Type of waste & $\mathbf{0 \%}$ & $\mathbf{3 0 \%}$ \\
\hline Rock wool - RW & & 1.198 \\
\hline Glass fiber - FG & & 1.171 \\
\hline Mixture - MIX & & 1.189 \\
\hline Reference - R & 1.250 & \\
\hline
\end{tabular}

\subsection{Test procedures}

Compressive strength $f_{c k}$, flexural strength $f_{c t m}$ and modulus of elasticity $E_{\mathrm{s}}$ of concretes with fibers were determined after 28 days of curing.

The fracture performance of concretes with fibers and control concrete without reinforcement was tested in accordance with the recommendations of RILEM Fracture Mechanics Committee [15,16]. The notched beams of size $100 \times 100 \times 400 \mathrm{~mm}$ were used for three-point bending test. The initial saw-cut notch with a depth equal to $30 \mathrm{~mm}$ and width of $3 \mathrm{~mm}$ was located in the mid-span place. The geometry of specimen and the way of load were presented in Fig. 1. The notches $\left(a_{0} / d=0.30\right)$ were sawn under wet conditions one day before the test. Each series was composed of 4 replicates.

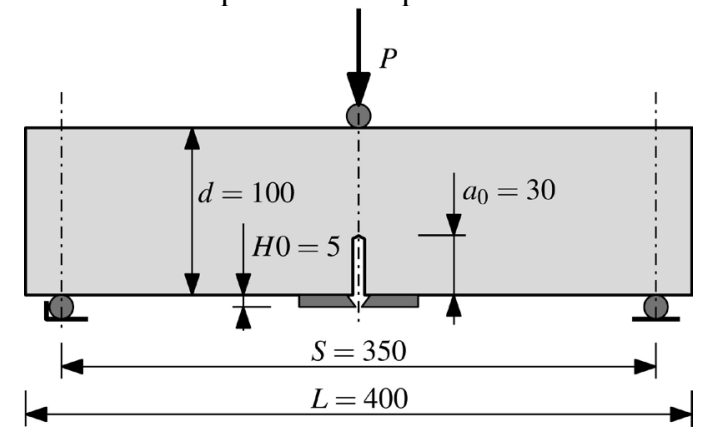

Fig. 1. Fracture testing configuration and geometry of notched specimen

The universal testing machine (MTS 322) with closed-loop servo control was used to achieve a stable failure of specimens. The crack mouth opening displacement (CMOD) measured at the center of the notch was a feedback signal. The load-deflection $(P-\delta)$ curves 
and load - crack mouth opening displacement $(P$-CMOD) were determined for the fracture process analysis. At the same time the complete load-time curve was recorded to check the stability during the test. Fig. 2 shows the testing machine with beam specimen.

The clip gauge was used to measure the CMOD values. The length of gauge was chosen in such a way that possible errors caused by the bending effects were avoided [18]. The rate of loading was controlled by the constant rate of increment of crack mouth opening displacement. The applied load was automatically reduced (unloading phase) when the load passed the maximum value and was about $95 \%$ of the peak load. When the applied load was reduced to ca. $100 \mathrm{~N}$, reloading was applied. The cycles of loading and unloading were repeated four times, and then the specimen was loaded up to failure.

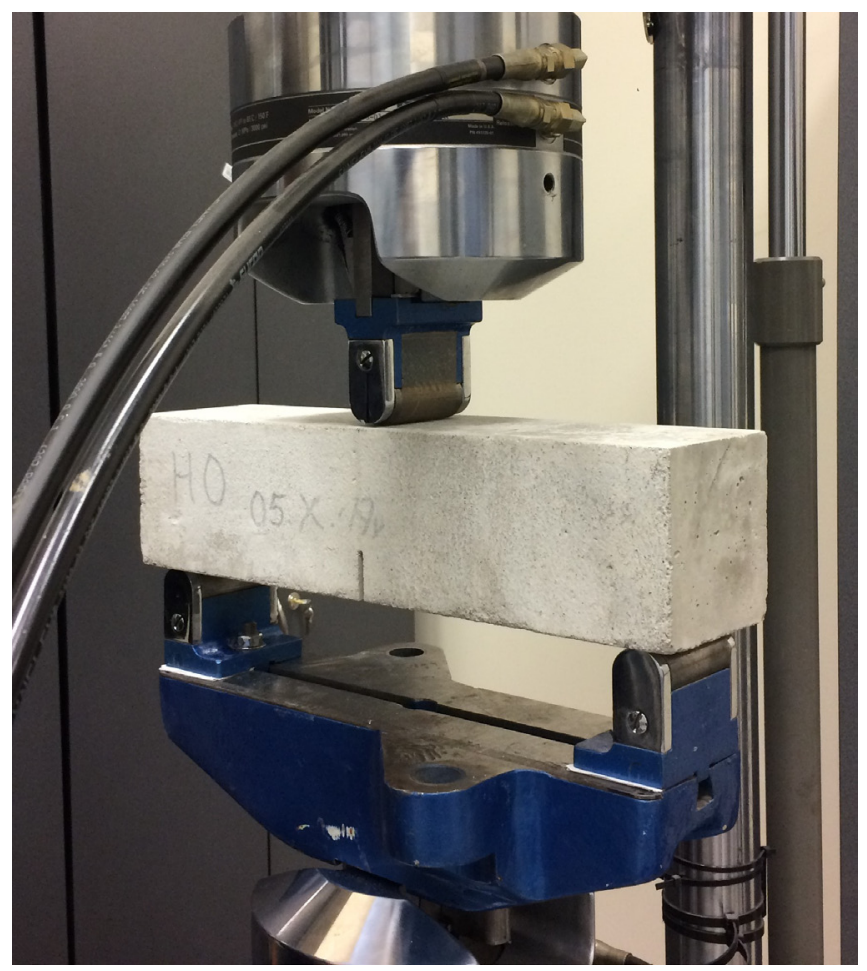

Fig. 2. Notched beam specimen during testing

The fracture parameters considered were the critical stress intensity factor $K_{\mathrm{Ic}}$ and the critical tip opening displacement $\mathrm{CTOD}_{c}$. The critical stress intensity factor $K_{\mathrm{I} c}$ is defined as the stress intensity factor calculated at the critical effective crack tip, using the measured maximum load. The critical crack tip opening displacement $\mathrm{CTOD}_{c}$ is defined as the crack tip opening displacement calculated at the original notch tip of the specimen, using the measured maximum load and the critical effective crack length $a_{c}$. A crack of given length ( $a_{0}=30 \mathrm{~mm}$ in current analysis) critically propagate when it reaches the length of $a_{c}$. Based on $K_{\mathrm{I} c}$ and $\mathrm{CTOD}_{c}$ the critical effective crack length $a_{c}$ was assessed. The parameters were determined using procedure and equations given in RILEM TC 89-FMT Recommendation [15]. based on the fracture model (TPFM) elaborated by Jenq and Shah [18], assuming cyclic loading-unloading test procedure. The assessments for LEFM application by Jenq and Shah were described in details in Shah et al. [19]. The way of using them in practice was presented e.g. by Bordelon [17] and Kosior-Kazberuk [20].

Both parameters are related to the critical stress $\sigma_{c}$ initiating the crack propagation and the effective length of the critical crack $a_{c}$ according to the following relationships: 


$$
\begin{aligned}
K_{I c}^{s} & =\sigma_{c} \sqrt{\pi a_{c}} g_{1}\left(\frac{a_{c}}{b}\right) \\
\mathrm{CMOD}_{c} & =\frac{4 \sigma_{c} a_{c}}{E} g_{2}\left(\frac{a_{c}}{b}\right) \\
\mathrm{CTOD}_{c} & =\mathrm{CMOD}_{c} g_{3}\left(\frac{a_{c}}{b}, \frac{a_{0}}{b}\right)
\end{aligned}
$$

where $g_{1}, g_{2}$, and $g_{3}$ are geometrical functions [19].

The specimens containing mineral wool fibers residues and control specimens without reinforcement were subjected to loading-unloading cycles repeated at least four times. The full $P$-CMOD diagrams with at least four loading-unloading cycles, obtained for specimens with and without fibers, were used to analyze the changes in compliance of the material during the fracture process.

The fracture energy $\left(G_{F}\right)$ is defined as the area under the load-deflection $(P-\delta)$ curve per unit fractured surface area. The fracture energy of basalt fiber reinforced concrete tested in this experimental study, was evaluated using the equation given by RILEM TC 50-FMT [15], in which the toughness was calculated from the area under load-deflection curves, obtained by performing a three-point bending test, dividing by the area of ligament, which is defined as the projection of the fracture zone on a plane perpendicular to the beam axis. The $P$ - $\delta$ diagram for calculation of total value of fracture energy $G_{F}$ and plastic $G_{F p l}$ and elastic $G_{F e l}$ parts of energy absorbed until crack propagation [21] was presented in Fig. 3.

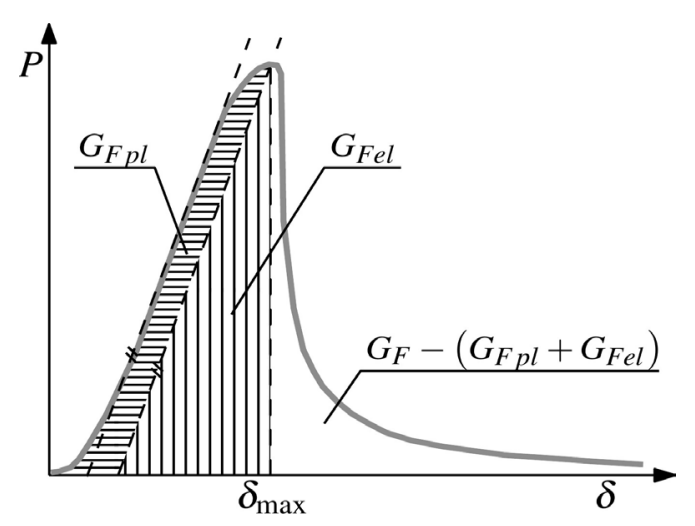

Fig. 3. Load $\mathrm{P}$ versus deflection $\delta$ diagram for fracture energy calculation

\section{Results}

The fracture parameters, such as the critical stress intensity factor $K_{\mathrm{I}}$, critical value of crack tip opening displacement $\mathrm{CTOD}_{c}$ and critical effective crack length $a_{c}$ were determined on the basis of $P-$ CMOD curves. The load $P$ plotted versus CMOD, measured for selected concretes with mineral wool fibers residues, were presented in Fig 4. Cross-sectional view of the specimen with the large amount of rockwool fibers was presented in Fig. 5. 


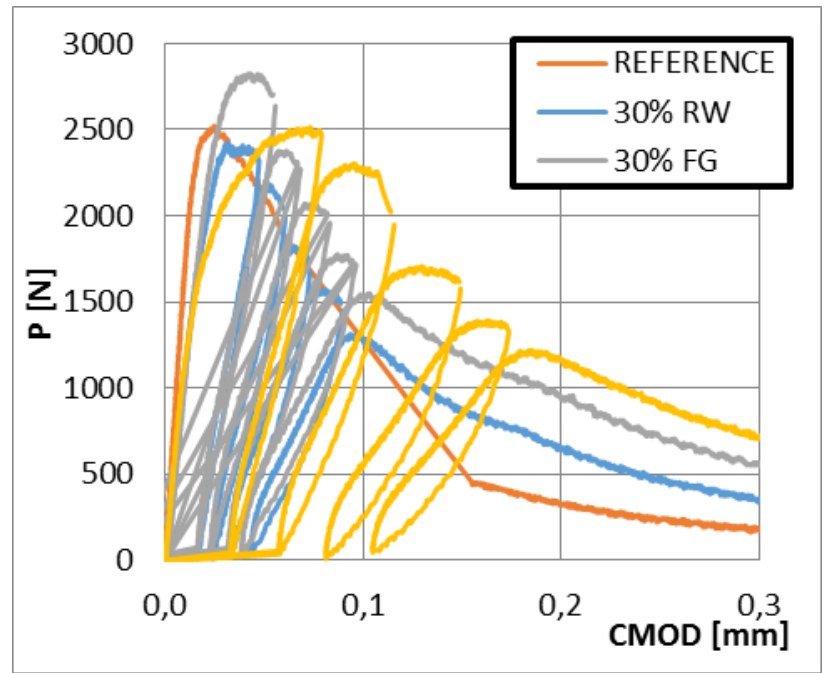

Fig. 4. Load $P$ versus CMOD curves for concretes with mineral wool fibers residues

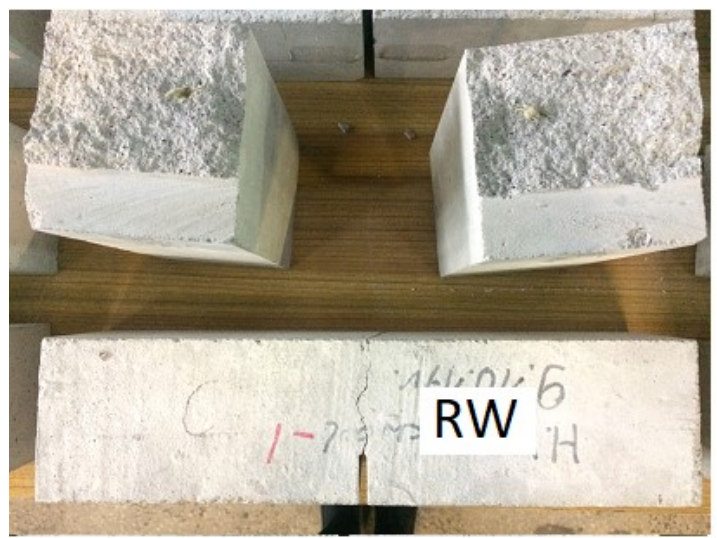

Fig. 5. Specimen with rockwool fibres after fracture parameter test

Considering the plots of $P$-CMOD, it should be noted that the longest segment of the first phase of the relationship (elastic phase) was obtained in case of concrete with fiberglass (FG). The CMOD growth is slight with increasing load. The shortest linear segments of plots were obtained for control concrete and for concrete with rockwool (RW) fibers. When analyzing the changes in the $P$-CMOD plots depending on the type of fiber waste, we can observe an increase in the maximum load (critical force) value. After reaching the maximum load, there was an unstable development of the cracks in concrete specimens. In the post-critical phase, the softening of material and a gradual decrease in load with increasing crack mouth opening displacement were observed. The descending part of the plot has increased for concrete with glass fibers and rockwool fibers, while in the case of concrete with mixed fibers this part of plot has been shortened. Although the value of the critical force in the series with mixed fibers was the smallest, the specimens were characterized by the highest compliance. In the last cycle of loading before destruction, the smallest loading force was observed for control concrete without fibres. We can conclude that glass fiber, rockwool and mix fibers improve the fracture mechanics parameters, reducing CMOD value and increasing the maximum load. 
The fracture mechanics parameters, presented in Table 3 , were determined on the basis of the $P$-CMOD plots using the formulas $(1,2,3)$. By comparing critical stress intensity factor $K_{I c}$, critical crack tip opening displacement $\mathrm{CTOD}_{\mathrm{c}}$ and critical effective crack length $a_{c}$, the significant effect of mineral wool fibers residues on the parameters mentioned was found. The value of fracture mechanics parameters increased where mineral wool fibers residues were added. The largest increase of parameters was observed for concrete where the mix of glass fiber and rockwool fibers were used. An increase in the $K_{I c}$ factor means greater resistance to concrete cracking. The highest $\mathrm{CTOD}_{\mathrm{c}}$ value was found for concrete with a mix of glass fiber and rockwool fibers.

Table 2. Fracture parameters of mineral wool fibers rediduesl reinforced concretes

\begin{tabular}{|l|l|l|l|l|}
\hline \multirow{2}{*}{ Parameter } & \multicolumn{4}{|l|}{ Fiber content (\% vol.) } \\
\cline { 2 - 5 } & R & RW & FG & MIX \\
\hline \multirow{2}{*}{$\boldsymbol{K}_{\mathbf{c} \boldsymbol{c}}\left(\mathbf{M N} / \mathbf{m}^{\mathbf{3} / \mathbf{2}}\right)$} & 0.5424 & 0.5780 & 0.8846 & 1.0364 \\
\hline $\boldsymbol{a}_{\boldsymbol{c}}(\mathbf{m m})$ & 30 & 35 & 48 & 60 \\
\hline $\mathbf{C T O D}_{\boldsymbol{c}}(\mathbf{m m})$ & 0.18 & 0.29 & 0.39 & 0.44 \\
\hline
\end{tabular}

For a complete understanding of the concrete behavior during the destruction, the fracture energy was analyzed. The load $P$ versus deflection $\delta$ curves were shown in Fig. 6 . The curves were used to determine the fracture energy of $G_{F}$. The presence of fibers increased the critical load and deflection of the specimens tested. Considering the shape of the curves the increase in deflection was the smallest for concrete with a mix of fibers, and it was the largest in the case of glass fiber concrete. The highest values of force in the postcritical phase (descending part of the plot) were observed for concrete with mixed fibres. For control concrete, the post-critical phase was the shortest.

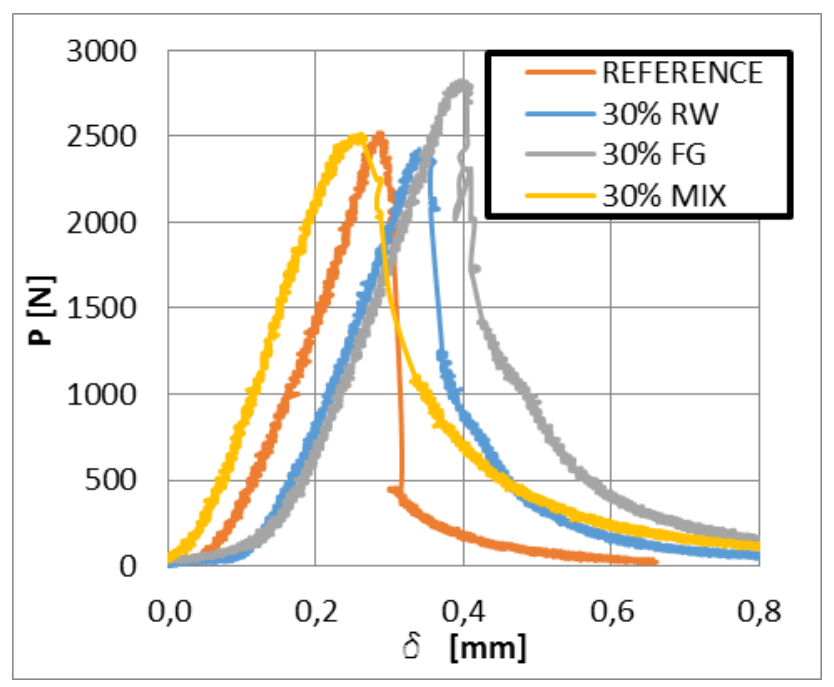

Fig. 6. Load $P$ versus deflection $\delta$ envelopes of concretes with mineral wool fibers residues

The mechanical characteristics and fracture energy determined for concretes with different content of mineral wool fibers residues were shown in Table 3. Mineral wool fibers residues improved the fracture toughness of concrete significantly, but these fibers had adverse effect on strength characteristics of concrete. It should be marked that fibers 
decreased the flexural tensile strength. The decreases in both the flexural and compressive strength of mineral wool fibers were significant. The addition of glass fiber caused the best effect in case of compressive and flexural strength. The incorporation of fibers slightly decreases the modulus of elasticity.

The enhancement of energy absorption was strongly affected by the type of fiber. In the series with mixed fibers, the fracture energy was almost 1.5 times higher than in control concrete.

Table 3. Mechanical test results of concretes with fibers residues

\begin{tabular}{|c|c|c|c|c|c|c|}
\hline & $\begin{array}{c}\text { Fiber } \\
\text { content } \\
(\% \text { vol. })\end{array}$ & $\begin{array}{c}\text { Compressive } \\
\text { strength } \\
(\mathrm{MPa})\end{array}$ & $\begin{array}{c}\text { Elastic } \\
\text { modulus } \\
(\mathrm{MPa})\end{array}$ & $\begin{array}{c}\text { Flexural } \\
\text { strength } \\
(\mathrm{MPa})\end{array}$ & $\begin{array}{c}\text { Maximum } \\
\text { load } \\
(\mathrm{N})\end{array}$ & $\begin{array}{c}\text { Fracture } \\
\text { energy } \\
\left(\mathrm{Nm} / \mathrm{m}^{2}\right)\end{array}$ \\
\hline REFERENCE & 0 & 33.26 & 22.92 & 2.70 & 2520 & 75 \\
\hline $\mathbf{3 0 \%}$ RW & 30 & 28.80 & 19.23 & 2.60 & 2425 & 83 \\
\hline $\mathbf{3 0 \%}$ FG & 30 & 29.10 & 18.22 & 3.30 & 2825 & 83 \\
\hline $\mathbf{3 0 \%}$ MIX & 30 & 27.56 & 18.89 & 2.92 & 2725 & 104 \\
\hline
\end{tabular}

As shown in Fig. 6, the incorporation of the mineral wool fibers residues does influence not only the post-cracking behaviour of concrete beam, but also the pre-cracking part of load-deflection curve. The values of the fracture energy given in Table 4 were calculated according to load-deflection diagram (Fig. 3) containing both the plastic and elastic parts of the fracture energy up to the breaking load. To give an idea about the relative and absolute proportion of the elastic part of the fracture energy, Table 4 illustrates elastic $G_{F e l}$ and plastic $G_{F p l}$ portion of energy until crack propagation related to the total measured energy $G_{F}$. The energy demand necessary for crack initiation increased with the addition of the fibers. It may be concluded that both elastic and plastic portions of energy increased.

Table 4. Elastic and plastic part of the fracture energy $G_{F}$ until crack propagation

\begin{tabular}{|l|l|l|l|l|l|}
\hline $\begin{array}{l}\text { Fiber content } \\
\text { (\% vol.) }\end{array}$ & $G_{F}$ & $G_{F p l}$ & $G_{F e l}$ & $G_{F p l}$ & $G_{F e l}$ \\
\cline { 2 - 6 } & $\left(\mathbf{N m} / \mathbf{m}^{2}\right)$ & $\left(\mathbf{N m} / \mathbf{m}^{2}\right)$ & $\left(\mathbf{N m} / \mathbf{m}^{2}\right)$ & $(\%)$ & $(\%)$ \\
\hline REFERENCE & 75 & 5 & 20 & 7 & 27 \\
\hline $\mathbf{3 0 \%}$ RW & 88 & 4 & 38 & 5 & 43 \\
\hline $\mathbf{3 0 \%}$ FG & 97 & 6 & 34 & 6 & 35 \\
\hline $\mathbf{3 0 \%}$ MIX & 104 & 11 & 28 & 11 & 27 \\
\hline
\end{tabular}

\section{Conclusion}

The mechanical properties of new composites with mineral wool residues in a cement matrix have been studied and discussed. The results obtained from the test, performed on concrete reinforced with various fiber, made it possible to analyse the fiber influence on fracture properties. The pre-peak behavior of material was slightly affected by the addition of fibers to the cement matrix. At this stage, the deformation regime was dominated by the cement matrix properties. The fibers caused a slight increase or an almost insignificant 
effect on the peak-load value, but the post-peak behavior revealed an important improvement compared to the reference concrete. Results of measuring toughness and energy-absorption characteristics showed that specimens with fibers acquire a great ductile behavior and energy absorption capacity, compared to ordinary concrete specimens. The mineral wool fibers residues caused the improvement of the fracture parameters as $K_{\mathrm{I} c}$, $\mathrm{CTOD}_{c}$ and $\delta_{\max }$ recorded for maximum load and total fracture energy $G_{F}$. The analysis of $P$-CMOD diagrams proved that the post-peak fracture behavior of the beam was greatly improved by the addition of wool fiber waste. The flexural strength increases with the incorporation of fiber waste in all cases, particularly for fiberglass residue. The compressive strength of composites with fibers decreases about 50\% compared to the concrete without fiber residues. It was found that the incorporation of waste of mineral wool to a cement mortar matrix is a viable alternative for its recycling.

This research work was financially supported by Ministry of Science and Higher Education, Poland; project number S/WBiIŚ/2/2017.

\section{References}

1. Europea Comision. Cerrar el círculo: un plan de acción de la Comisión al Parlamento Europeo, al Consejo, al Comité Económico y Social Europeo y al Comité de las Regiones. Bruselas. p. 1-4, (2015).

2. Sáez V., del Río Merino P., \& Porras-Amores M., C. Estimation of construction and demolition waste volume generation in new residential buildings in Spain. Waste Management \& Research, 30(2), 137-146. (2012).

3. Romaniga Pineiro S., del Rio Meriono M., Perez Garcia C., New plaster composite with mineral wool fibers from $C D W$ recycling. Advances in Materials Science and Engineering, vol. 2015, p. 1, (2015).

4. Vantsi O., Karki T., Mineral wool waste in Europe: a review of mineral wool waste quantity, quality, and current recycling methods. Journal of Material Cycles and Waste Management, vol. 16, no 1, p. 62-72. (2014).

5. Lawrence M., Reducing the environmental impact of construction by using renewable materials. Journal of Renewable Materials, vol. 3, no 3, p. 163-174. (2015).

6. Walker R., Pavia S., Effect of Hemp'S Soluble Components on the Physical Properties of Hemp Concrete. Journal of Materials Science Research, vol. 3, no 3, p. 12. (2014).

7. Haas W., et al. How circular is the global economy?: An assessment of material flows, waste production, and recycling in the European Union and the world in 2005. Journal of Industrial Ecology, vol. 19, no 5, p. 765-777. (2015).

8. DU H., TAN K. H., Waste glass powder as cement replacement in concrete. Journal of Advanced Concrete Technology, vol. 12, no 11, p. 468-477. (2014).

9. Zhi G., Renjuan S., Kun Z., Zhili G.,Pengcheng L., Physical and mechanical properties of mortar using waste Polyethylene Terephthalate bottles. Construction and Building Materials, vol. 44, p. 81-86. (2013).

10. Halvaei, M., Jamshidi, M., \& Latifi, M. Application of low modulus polymeric fibers in engineered cementitious composites. Journal of industrial textiles, 43(4), p. 511-524. (2014).

11. Jamrozik, E. D., De Klerk, N., \& Musk, A. W. Asbestos-related disease. Internal medicine journal, 41(5), p. 372-380. (2011). 
12. Pakravan, H. R., Jamshidi, M., \& Latifi, M. Investigation on polymeric fibers as reinforcement in cementitious composites: Flexural performance. Journal of industrial textiles, 42(1), p. 3-18. (2012).

13. Kosior-Kazberuk M., Krassowska J., Fracture behaviour of basalt and steel fiber reinforced concrete. Budownictwo i Inżynieria Środowiska, vol. 6, p. 73-80. (2015).

14. Juárez-Alvarado, C. A., González López, J. R., Mendoza-Rangel, J. M., \& Zaldivar Cadena, A. A. Compuestos cementantes fibroreforzados de bajo impacto ambiental comportamiento mecánico. Revista de la Asociación Latinoamericana de Control de Calidad, Patología y Recuperación de la Construcción, 7(2), p. 45, (2017).

15. Recommendation TC 50-FMT RILEM. Determination of the fracture energy of mortars and concretes by means of three-point bend tests on notched beams. Materials and Structures, 18, p. 285-290. (1985).

16. Recommendation TC 89-FMT RILEM. Determination of fracture parameters ( $K_{I c}^{s}$ and $C T O D_{c}$ ) of plain concrete using three-point bend test. Materials and Structures, 23, p. 457-460. (1990).

17. Bordelon AC. Fracture behavior of concrete materials for rigid pavements system. MA Thesis. Graduate College of University of Illinois at Urbana-Champaign, USA, (2007).

18. Jenq YS, Shah SP. Two parameter fracture model for concrete. Journal of Engineering mechanics, 111, p. 1227-1241. (1985).

19. Shah SP, Swartz SE, Ouyang Ch. Fracture mechanics of concrete: Applications of fracture mechanics to concrete, rock and other quasi-brittle materials. John Wiley \& Sons,Inc., New York, (1995).

20. Kosior-Kazberuk M. Variations in fracture energy of concrete subjected to cyclic freezing and thawing. Archives of Civil and Mechanical Engineering, 13, p. 254-259. (2013).

21. Voit K, Kirnbauer J. Tensile characteristics and fracture energy of fiber reinforced and non-reinforced ultra high performance concrete (UHPC). International Journal of Fracture, 188, p. 147-157. (2014). 